\title{
Acquisition Processes in Adaptive Antenna Systems
}

Jensen, E. Voel; Aagaard, Hans J.

Published in:

3rd European Microwave Conference

Link to article, DOI:

10.1109/EUMA.1973.331799

Publication date:

1973

Document Version

Publisher's PDF, also known as Version of record

Link back to DTU Orbit

Citation (APA):

Jensen, E. V., \& Aagaard, H. J. (1973). Acquisition Processes in Adaptive Antenna Systems. In 3rd European Microwave Conference (Vol. Volume 2, pp. 1-4). IEEE. https://doi.org/10.1109/EUMA.1973.331799

\section{General rights}

Copyright and moral rights for the publications made accessible in the public portal are retained by the authors and/or other copyright owners and it is a condition of accessing publications that users recognise and abide by the legal requirements associated with these rights.

- Users may download and print one copy of any publication from the public portal for the purpose of private study or research.

- You may not further distribute the material or use it for any profit-making activity or commercial gain

- You may freely distribute the URL identifying the publication in the public portal

If you believe that this document breaches copyright please contact us providing details, and we will remove access to the work immediately and investigate your claim. 
E. Voel Jensen and Hans J. Aagaard

Laboratory of Electromagnetic Theory

Technical University of Denmark

DK-2800, Lyngby, Denmark

\section{Introduction}

Signal processing schemes for adaptive receiving antenna arrays have been analyzed in computer simulation experiments. A major part of the experiments consists of detailed studies of the acquisition process, i.e. the automatic or adaptive adjustment of the system in response to an input signal structure comprising a wanted signal, internal Gaussian noise and interference from distant sources.

The acquisition process of the adaptive antenna system results in capturing the wanted signal and more or less efficient attenuation or rejection of unwanted noise and interference. The simulated systems all belong to the general class of receiving arrays with automatic or adaptive signal processors using predetection combining.

The purpose of this paper is to demonstrate that computer simulation techniques can be readily used in comparative studies of various types of arrays and signal processors.

\section{Principles of adaptive antenna systems}

Fig. I shows a simplified functional diagram of an adaptive antenna system. The diagram is so comprehensive that it can be applied to the various types of systems that have been investigated.

In an adaptive antenna system, it is necessary to provide some cues by which the system will be able to perform the signal extracting process where the wanted signal is recognized and distinguished from unwanted noise and interference. Such cues may be imbedded in the system, and additional information regarding direction or content of the wanted signal may be required.

In Fig. I, fundamental methods of introducing a cue or a reference are illustrated by means of a 4-position switch, the reference signal selector, which may not be present in a final system implementation. However, connections corresponding to the switch positions are actually present in the following three types of systems that have been investigated in the computer simulations.

1) Adaptive multichannel processor using regular iteration algorithm for optimization of signal-to-noise ratio through automatic adjustment of the electronic gain in each channel. Adaptive processors of this type were originally developed for sonar and seismic systems and are now being considered with growing interest for use in radio communication systems $[1],[2],[3],[4]$. 


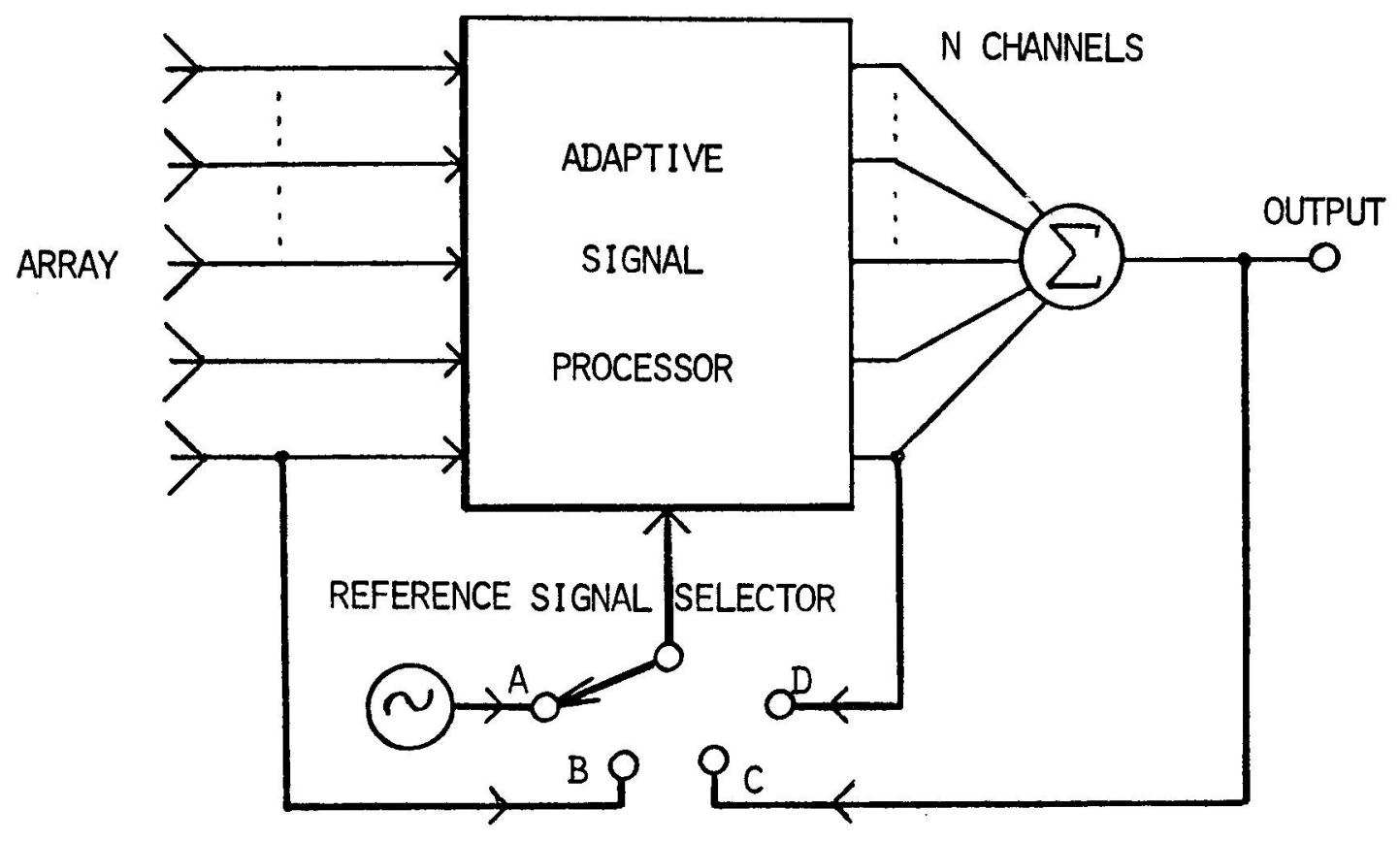

FIG, 1

ADAPTIVE ANTENNA SYSTEM

2) Conjugate-correlator system. The adjustable complex gain factor in each channel is formed by cross correlating the complex conjugated input signal and the reference signal [4].

3) Phase-locked system. Automatic phase adjustment in each channel is performed in a multichannel superheterodyne receiver with phase-lock loop (PLI) circuits. Several kinds of filtering, limiting and adaptive loop parameter adjustment can be incorporated in the system [5].

Acquisition processes

The simulation experiments cover various cases of linear, circular and rectangular arrays. The results are collected in computer generated plots comprising signal curves, learning curves, error curves, curves for signal-to-noise ratio and sequences of radiation patterns evolved during the acquisition process.

Examples of results from computer runs with the adaptive multichannel processor and the phase-locked system are illustrated in Figs. 2-3. Specifications covering these examples are given in table $I$.

The learning curves in Fig. 2 demonstrate that fast acquisition can be achieved in the adaptive multichannel processor by choosing proper values of a feedback factor $C$. Furthermore, the curves illustrate how an increase in the rate of acquisition involves degradation of the noise and stability properties of the system.

The more elaborate plot data in Fig. 3 from the phase-lock system show how the phase of the voltage controlled oscillators (VCO) in each channel acquires a final value within an error range determined by the level of noise and interference. Development of the radiation pattern during acquisition is clearly influenced not only by the wanted signal (S) but also by interference (I) and noise.

In the investigated systems, the best acquisition performance is obtained in the cases where the reference signal is provided from a local noisefree generator. 
CHANNEL

GAIN

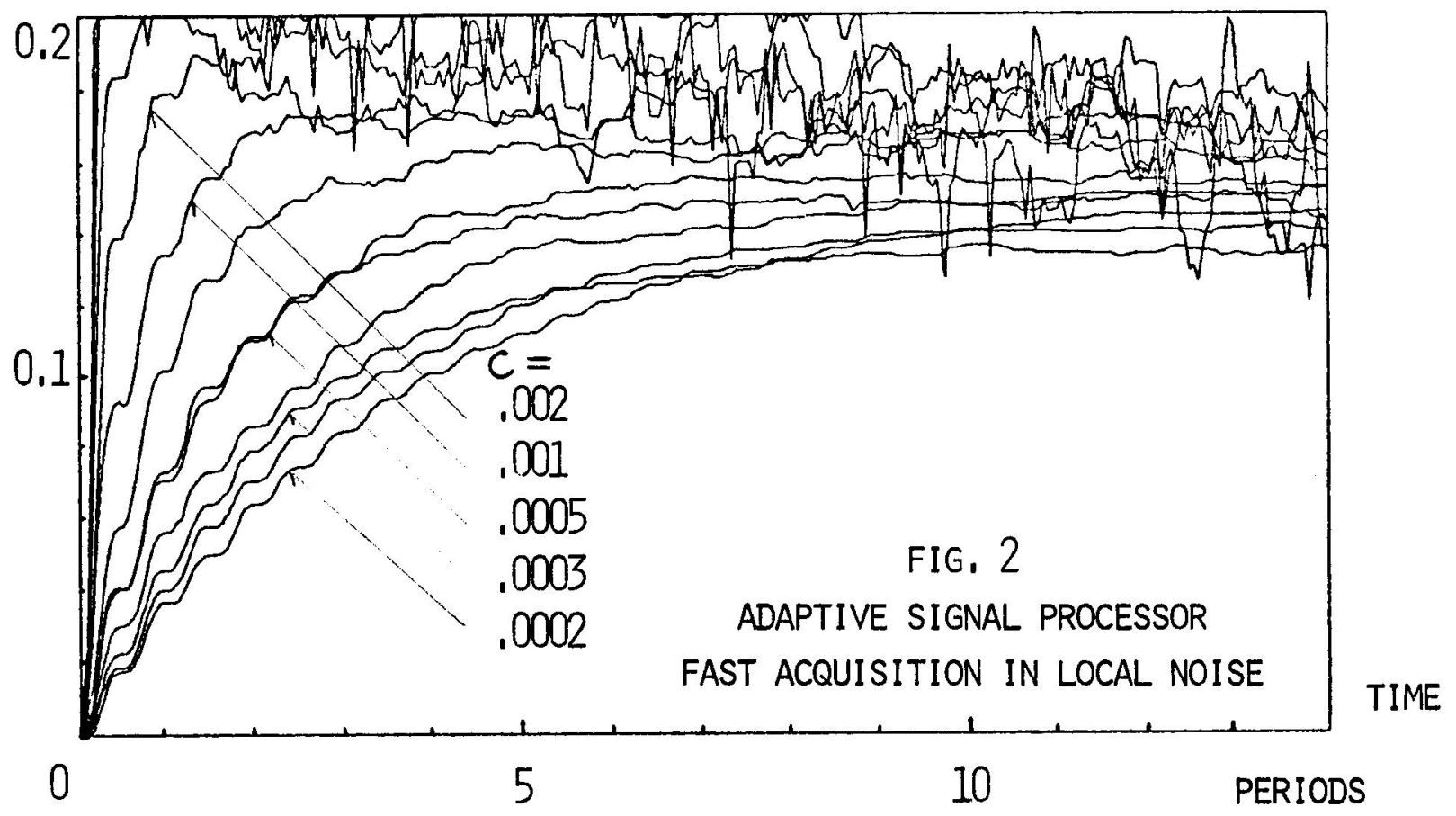

\section{Table I}

\section{Specifications for computer simulation experiments}

System:

Reference signal:

Selector position (Fig. 1): A

Array:

Signal level:

CW-interference level:

Gaussian noise level:

Computer: .

Program:

Signal representation:

Processing time (CPU):
Adaptive signal processor

(Fig. 2)

Local generator
Phased locked system (Fig. 3)

Local generator

A

Circular array, $\mathrm{N}=7$ isotropic elements, radius $\mathrm{R}=2 \lambda$

$10 \mathrm{~dB}$

$-6 a B$

$-6 \mathrm{~dB}$

Narrow band, $O \mathrm{~dB}$

Wideband, $0 \mathrm{~dB}$

IBM $370 / 165$ at NEUCC, Tech. Univ. of Denmark, Lyngby

"ADA $7 "(P L / I)$

PLL (FORTRAN)

Real

Complex

$449 \mathrm{sec}$ (13 runs)

$40 \sec (1$ run $)$ 


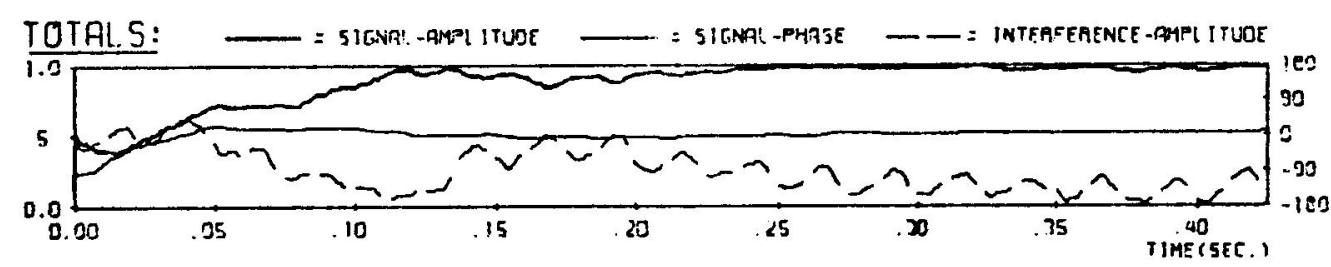

VCO - PHASE - ERROR:

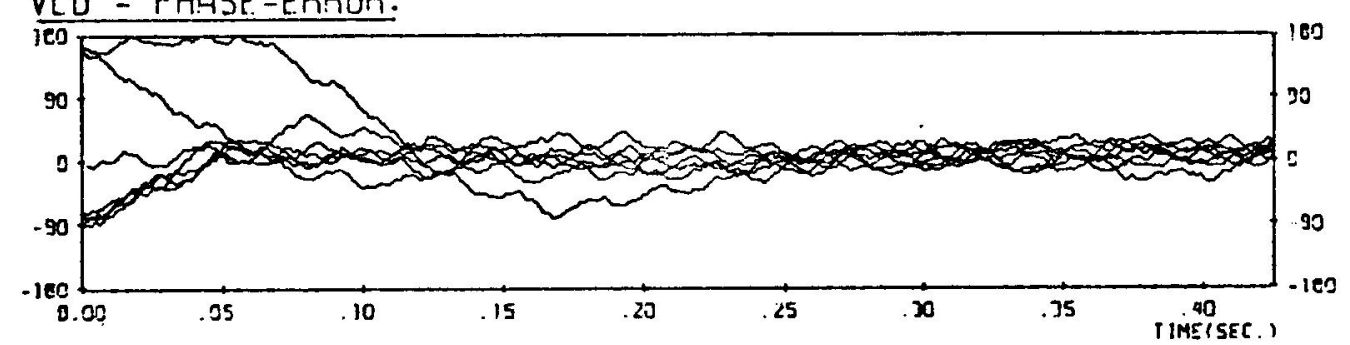

RADIATION PATTERN:
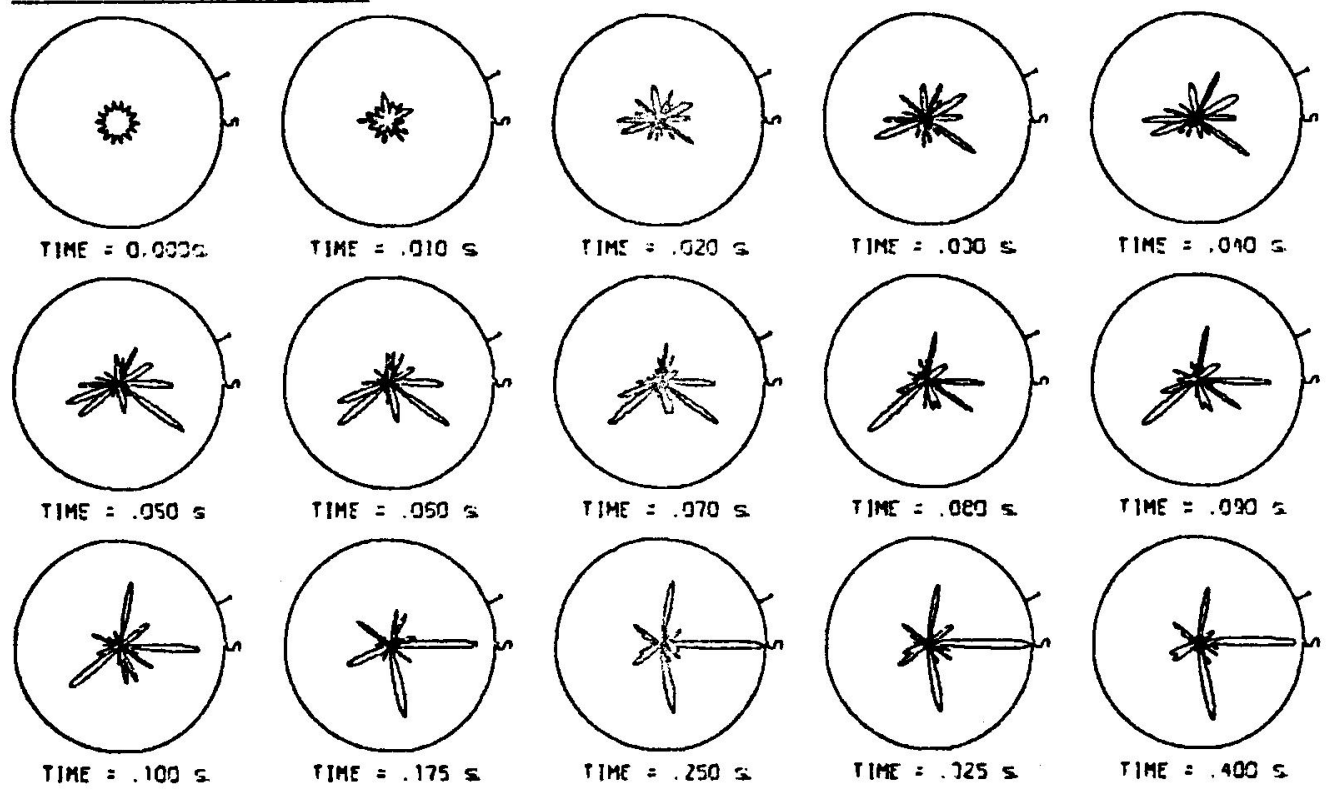

TIME $=.910 \mathrm{~s}$

rIME $=.020=$

IIME $=.030 \mathrm{~s}$

TIME $=.040=$
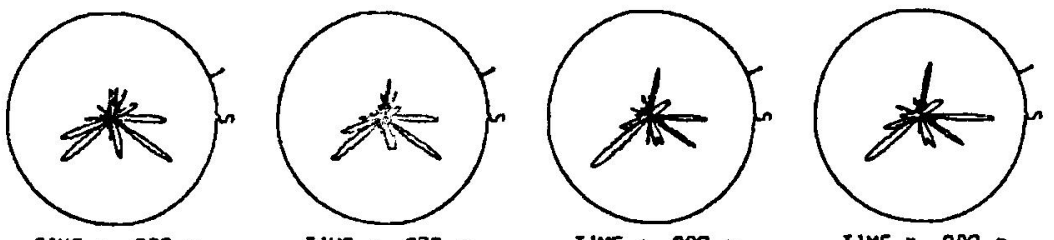

TIME : . $970 \mathrm{~s}$

TIME $=.0095$

TIME $=.030 \%$
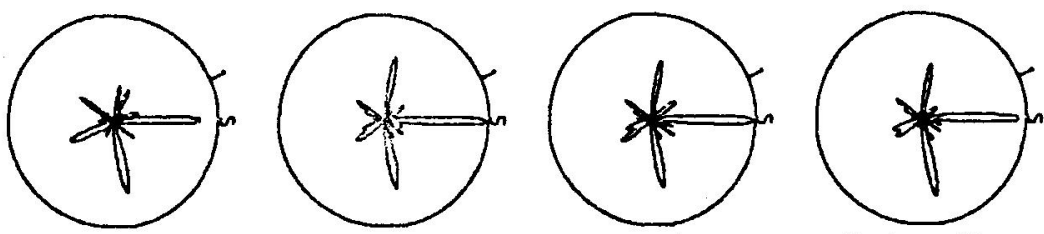

TIME $=.175 \mathrm{~s}$

$\operatorname{TIME}=.250=$

TIME = . $325 \mathrm{~s}$

TIME $=.4005$

FIG, 3

PHASE-LOCKED ANTENNA SYSTEM

ACQUISITION IN NOISE AND CW-INTERFERENCE

\section{References}

1. Compton, R.T., "Adaptive antenna arrays for aircraft communication systems," Ohio State University, Rep. 3098-2, January 1972, 119 pp.

2. Frost, O.I., "An algorithm for linearly constrained adaptive array processing," Proc. IEEE, vol. 60, No. 8, August 1972, pp. 926-935.

3. Zahm, C.L., "Application of adaptive arrays to suppress strong jammers in the presence of weak signals," IEEE Trans. Aerospace \& Electronic Syst., vol. AES-9, No. 2, March 1973, pp. 260-271.

4. Jensen, E.V., "Computer simulation of adaptive antenna systems," Laboratory of electromagnetic Theory, Rep. R 109, December 1972, 68 pp.

5. Aagaard, H.J., "Computer simulation of phase locked antenna systems," Laboratory of electromagnetic Theory, Rep. R 118, 1973. 